\title{
BMJ Open Redesigning the 'choice architecture' of hospital prescription charts: a mixed methods study incorporating in situ simulation testing
}

\author{
Dominic King, ${ }^{1}$ Ali Jabbar, ${ }^{2}$ Esmita Charani, ${ }^{3}$ Colin Bicknell, ${ }^{1}$ Zhe Wu, ${ }^{4}$ \\ Gavin Miller, ${ }^{4}$ Mark Gilchrist, ${ }^{4}$ Ivo Vlaev, ${ }^{1}$ Bryony Dean Franklin, ${ }^{5}$ Ara Darzi ${ }^{1}$
}

To cite: King D, Jabbar A, Charani $\mathrm{E}$, et al. Redesigning the 'choice architecture' of hospital prescription charts: a mixed methods study incorporating in situ simulation testing. BMJ Open 2014;4:e005473.

doi:10.1136/bmjopen-2014005473

- Prepublication history and additional material is available. To view please visit the journal (http://dx.doi.org/ 10.1136/bmjopen-2014005473).

Received 14 April 2014 Revised 26 September 2014 Accepted 6 October 2014

CrossMark

For numbered affiliations see end of article.

Correspondence to Dr Dominic King; dominic.king@imperial.ac.uk

\section{ABSTRACT}

Objectives: To incorporate behavioural insights into the user-centred design of an inpatient prescription chart (Imperial Drug Chart Evaluation and Adoption Study, IDEAS chart) and to determine whether changes in the content and design of prescription charts could influence prescribing behaviour and reduce prescribing errors.

Design: A mixed-methods approach was taken in the development phase of the project; in situ simulation was used to evaluate the effectiveness of the newly developed IDEAS prescription chart.

Setting: A London teaching hospital.

Interventions/methods: A multimodal approach comprising (1) an exploratory phase consisting of chart reviews, focus groups and user insight gathering (2) the iterative design of the IDEAS prescription chart and finally (3) testing of final chart with prescribers using in situ simulation.

Results: Substantial variation was seen between existing inpatient prescription charts used across 15 different UK hospitals. Review of 40 completed prescription charts from one hospital demonstrated a number of frequent prescribing errors including illegibility, and difficulty in identifying prescribers. Insights from focus groups and direct observations were translated into the design of IDEAS chart. In situ simulation testing revealed significant improvements in prescribing on the IDEAS chart compared with the prescription chart currently in use in the study hospital. Medication orders on the IDEAS chart were significantly more likely to include correct dose entries (164/164 vs $166 / 174 ; p=0.0046)$ as well as prescriber's printed name (163/164 vs 0/174; $p<0.0001)$ and contact number ( $137 / 164$ vs $55 / 174$; $\mathrm{p}<0.0001)$. Antiinfective indication ( $28 / 28$ vs $17 / 29$; $p<0.0001)$ and duration (26/28 vs $15 / 29 ; p<0.0001)$ were more likely to be completed using the IDEAS chart.

Conclusions: In a simulated context, the IDEAS prescription chart significantly reduced a number of common prescribing errors including dosing errors and illegibility. Positive behavioural change was seen without prior education or support, suggesting that some common prescription writing errors are potentially rectifiable simply through changes in the content and design of prescription charts.

\section{Strengths and limitations of this study}

- The Imperial Drug Chart Evaluation and Adoption Study (IDEAS) chart was the result of an intensive exploration of stakeholders' views and observations of their behaviour in relation to the prescription and administration of medications.

- The design of the IDEAS chart incorporated cutting edge behavioural insights using the Mindspace framework for behaviour change.

- The use of in situ simulation testing enhances the realism of health professionals completing the chart without risking patient safety through the trial of an untested prescription chart.

- This study is limited by relatively small sample size and the use of simulation rather than a formal clinical evaluation. A formal sample size calculation was not undertaken for this preliminary study.

- A number of parts of the IDEAS chart (checklist separate sections for oxygen and intravenous fluid prescribing) were not tested as part of the evaluation. It was not possible to determine the relative contribution of the different features implemented.

\section{INTRODUCTION}

The prescription and administration of medicines is the most common therapeutic intervention in healthcare settings. ${ }^{1}$ Medication errors are common. ${ }^{2}$ Such errors are of concern, as they can have a significant impact on clinical outcomes and come with a heavy cost burden. ${ }^{3}$ Given the impact of medication errors, efforts have been directed at identifying when they occur and how they can be avoided. $^{4}$

Medication errors are generally classified by the stage at which they occur: prescribing, dispensing or administration. ${ }^{5}$ Safe and effective prescribing of medications requires the identification of the need for a drug and selection of the correct drug, together with the route, form, dose, frequency and duration, for the individual patient'. ${ }^{6}$ Prescribing has been 
identified as the stage at which most errors occur and is thus an important target for improvement. ${ }^{7}$ Prescribing errors are a common occurrence in hospital inpatients, affecting an estimated $7 \%$ of medication orders, $2 \%$ of patient days and $50 \%$ of hospital admissions in hospitals using paper-based prescription charts. ${ }^{8}$

The vast majority of National Health Service (NHS) hospitals continue to use traditional paper prescription charts for hospital inpatients; these are used both for prescribing medicines and to record their administration. ${ }^{9}$ Concerns have been raised about the contributory role of poorly designed prescription charts in facilitating prescribing errors. ${ }^{10}$ While a standardised inpatient prescription chart exists for Wales, hospitals across the rest of the UK have different charts often with very different features. The UK Academy of Medical Royal Colleges (AoMRCs) released guidelines in 2011 detailing an expert panel's view of the essential components of a safe and effective chart and there has been support by a number of Medical Royal Colleges and organisations such as the General Medical Council for a move towards a national prescription chart in England. ${ }^{11}$ A recommendation from the General Medical Council-commissioned 'EQUIP' study was that 'a standard drug chart should be introduced throughout the NHS', although there is not necessarily evidence to support this approach. ${ }^{12}$

The tools traditionally used to support good prescribing are largely informed by the theory of 'rational choice' ${ }^{13}$ This approach predicts that if prescribers are given the right information and training then they will reliably make good prescribing decisions. However, educational initiatives in therapeutics have often failed to demonstrate significant improvements in prescribing, ${ }^{14}$ with prescribers regularly failing to follow basic prescribing instructions such as writing legibly, writing the dose clearly and documenting the length of treatment. ${ }^{15}$

A second potential strategy to change prescribers' behaviour is built on four decades of applied research in behavioural economics-and the wider behavioural sciences-that finds that much of the time people act automatically, without really thinking about their decisions, often making predictable errors of judgment. Behavioural economics, which combines insights from psychology with the laws of economics, demonstrates that decision-making is strongly influenced by the environment or context in which choices are made. ${ }^{16}{ }^{17}$ In addition to helping us better understand why people are 'predictably irrational', ${ }^{18}$ behavioural economics also provides us with new tools that can alter the 'choice architecture' as Thaler and Sunstein ${ }^{19}$ call it in their influential book Nudge. Choice architecture describes the way in which decisions can be influenced by how choices are presented. It is proposed that interventions that are based on changing the choice architecture 'typically require little conscious engagement on the part of the individual to realise their intended effects, working via automatic or non-conscious psychological processes'. ${ }^{20}$ We focus here on the role of the design and content of inpatient prescription charts as a moderator of prescribing behaviour.

This paper describes the Imperial Drug Chart Evaluation and Adoption Study (IDEAS), which considered how the choice architecture (the design and content) of prescription charts could influence prescribing behaviour building on the recommendations from the AoMRC report. ${ }^{11}$ While there is existing evidence that differences in prescription chart design can lead to significant variations in prescribing error rates, ${ }^{6}{ }^{21}$ there is a lack of research into how a direct behavioural and user-centred approach to the design of paper prescription charts can influence prescribing behaviour.

\section{Aim and objectives}

Our aim was to evaluate whether a user-centred approach incorporating behavioural insights could enhance prescribing behaviour and reduce prescription errors in the inpatient setting. Our objectives were to take a usercentred approach to the redesign of a paper inpatient prescription chart, incorporating insights from behavioural economics, and to evaluate the impact of such changes on prescribing behaviour via an in situ simulation.

\section{METHODS}

Setting

The IDEAS study took place at Imperial College Healthcare NHS Trust (ICHNT), a large London teaching hospital trust with three main hospital sites. This trust operates a typical UK model for the prescribing, supply and administration of medication, in which prescribers handwrite medication orders onto a formatted inpatient prescription chart. The same prescription chart is also used by nursing staff to determine what medications are to be given to each patient, and to then record their administration. Charts are routinely reviewed by pharmacists to check that medication orders are legible, legal and clinically appropriate. The existing chart in clinical use is here referred to as the ICHNT chart.

The multidisciplinary project team comprised four physicians, two behavioural scientists, four pharmacists and two graphic designers. The project took place between August 2011 and September 2013 and comprised three parts: (1) an exploratory phase to identify problems associated with current inpatient prescription charts; (2) iterative design of the IDEAS prescription chart; and (3) in situ simulation testing of the IDEAS chart in comparison with the ICHNT chart. The study was approved as a service evaluation within ICHNT; ethics approval was not required. Written consent was obtained from each participating healthcare professional. All data collected were anonymous and confidential.

\section{Phase 1: exploratory phase}

The initial exploratory phase employed several strategies.

First, a review of hospital prescription charts from across the UK was performed. A team of two physicians, 
one behavioural scientist and two design experts reviewed a convenience sample of 15 prescription charts from different hospitals and made a number of observations against specific criteria informed by the guidelines produced by the AoMRC. ${ }^{11}$

Second, two physicians reviewed the anonymised prescription charts of 40 consecutive patients discharged from one medical and one surgical inpatient ward, assessing the charts against a predefined list of criteria including legibility of medication orders, completion of allergy status and usage of different sections of the chart (eg, oxygen, once only medications).

Third, two focus groups were held. A diverse group of seven participants (two physicians, three hospital-based pharmacists and two hospital-based nursing staff) were recruited to each of the two focus groups to maximise the exploration of different perspectives. Each focus group was scheduled to last for $75 \mathrm{~min}$ and was moderated by a member of the project team. No reimbursement was paid and verbal consent was obtained from participants prior to start. Audio recording was undertaken using RecordPad software and transcriptions made. The focus group sessions were structured in two parts. The first explored participants' general perspectives on the prescribing process and opinions on prescription charts they had personal experience of using in clinical practice. The second part explored participants' views on some different prescription chart design ideas presented to them by the moderator.

Finally, two designers with expertise in user research and insight gathering carried out 3 days of observations of physicians, pharmacists and nurses prescribing, verifying and administering medication, accompanied by a physician. Electronic notes of observations were made.

\section{Phase 2: design of IDEAS prescription chart}

Two specific approaches were taken in developing the IDEAS prescription chart. First, an iterative, user-centred approach incorporating insight gathering from the exploratory phase of the study was used in arriving at the final design templates for the IDEAS prescription chart. Second, the Mindspace framework was used to design interventions or 'nudges' to influence prescriber behaviour. ${ }^{17}$ Mindspace is a widely used framework for behaviour change that collects together insights from behavioural economics in the Mindspace mnemonic (table 1).

\section{Phase 3: in situ simulated pilot testing of the IDEAS prescription chart}

A simulated patient case study was developed to test the main changes incorporated within the IDEAS chart. The case study included a request for two antibiotic prescriptions plus 10 further medications to be prescribed. The simulated patient also had a documented allergy with a specific reaction. The case was developed by a team of physicians and pharmacists and pilot tested on two physicians prior to formal testing. We aimed to recruit 30

\begin{tabular}{|c|c|}
\hline $\begin{array}{l}\text { Mindspace } \\
\text { effect }\end{array}$ & Description \\
\hline Messenger & $\begin{array}{l}\text { We are heavily influenced by who } \\
\text { communicates information }\end{array}$ \\
\hline Incentives & $\begin{array}{l}\text { Our responses to incentives are shaped } \\
\text { by predictable mental shortcuts such as } \\
\text { strongly avoiding losses }\end{array}$ \\
\hline Norms & $\begin{array}{l}\text { We are strongly influenced by what } \\
\text { others do }\end{array}$ \\
\hline Defaults & We 'go with the flow' of preset options \\
\hline Salience & $\begin{array}{l}\text { Our attention is drawn to what is novel } \\
\text { and seems relevant to us }\end{array}$ \\
\hline Priming & $\begin{array}{l}\text { Our acts are often influenced by } \\
\text { subconscious cues }\end{array}$ \\
\hline Affect & $\begin{array}{l}\text { Our emotional associations can } \\
\text { powerfully shape our actions }\end{array}$ \\
\hline Commitment & $\begin{array}{l}\text { We seek to be consistent with our public } \\
\text { promises, and reciprocate acts }\end{array}$ \\
\hline Ego & $\begin{array}{l}\text { We act in ways that make us feel better } \\
\text { about ourselves }\end{array}$ \\
\hline
\end{tabular}

foundation level (junior) doctors over a 4-week period, who were each asked to read the case study before being randomly allocated to prescribe the medication required using the ICHNT chart or the IDEAS chart. No training was provided on the use of either chart although all participants were already familiar with using the ICHNT chart in their clinical practice.

To enhance realism, prescribers completed the assessment during normal working hours in actual patient care units (eg, ward or emergency department). Such in situ simulation, physically integrated into the clinical environment, provides greater realism than similar simulations in an alternative environment such as a classroom setting. ${ }^{22}$ Completed prescription charts were audited against predetermined standards for safe and good quality prescription writing (see online supplementary appendix 1).

\section{Analysis}

In the exploratory phase, the different prescription charts in use across the NHS as well as the 40 completed prescription charts were subject to evaluation against the predetermined criteria. Focus group and observational data were thematically analysed and agreement sought between two reviewers over key findings. In reference to the charts completed in the insitu simulations, one physician and one pharmacy student separately examined the prescription charts. Data were entered into Excel and then transferred to SPSS (V.22.0. Armonk, New York, USA: IBM Corp) for analysis. For each of the different prescription tasks, we wanted to test whether there was a significant difference between the IDEAS and ICHNT charts for a range of different outcome measures (eg, completion of information on indication or duration of anti-infectives, ability to identify the 
prescriber). Fisher's exact test with a Holm-Bonferroni correction was used to correct for false-positive results arising from multiple comparisons. This allows for a family-wise significance level of 0.05 , while maintaining good power.

\section{RESULTS}

\section{Phase 1: exploratory phase}

There was wide variety in terms of design and content between the 15 different NHS prescription charts examined (see online supplementary appendix 2). Most charts used a booklet format; these ranged in length from 6 to 12 pages. All charts examined-including the ICHNT chart-failed on at least one of the AoMRC standards for the design of hospital prescription charts. $^{11}$

A review of 40 completed prescription charts at ICHNT revealed that demographic information about the patient was generally completed to a high standard. Allergies were documented for 10/40 (25\%) patients although the complete type of reaction was only fully completed for $3 / 10(30 \%)$ of these. Overall, 22/350 $(6 \%)$ of the 'regular' medication orders and 10/101 $(10 \%)$ of the 'as required' medications reviewed were deemed illegible by the reviewers and as such constituted a prescribing error. ${ }^{23}$ For $313 / 350(89 \%)$ of the 'regular' medication orders and 92/101 (91\%) of 'as required' medications, the prescriber could not be identified. Antibiotics were prescribed for 18/40 (45\%) of the patients at some point during their inpatient stay. The indication was documented for only 21/40 (53\%) of the antibiotic orders prescribed and the length of course specified for $8 / 40(20 \%)$ of these (see online supplementary appendix 3 ).

In our two focus groups, recurring themes included an explicit dislike across the professions for multiple different charts being used for the same patient. All professional groups felt that prescription errors-particularly illegibility-were often 'tolerated' and that medications were occasionally administered even if key details were missing. Doctors in the group felt that pharmacists would spot and rectify errors before any harm was caused. When the groups were asked for reasons underlying prescription errors a suggestion put forward was that junior medical staff often completed prescriptions. Some prescribers commented that the format of the prescription chart made it difficult to enter all the details requested. When reviewing some specific design and layout ideas for prescription charts, there was general support for the use of 'booklets', a better way of indexing sections, and a more structured way of using colour across the charts presented. There was interest in the use of checklists on the chart but no agreement on what the contents of the checklist should be.

Insight gathering through the shadowing of prescribers, nursing staff and pharmacists in different clinical areas found that prescribers were in a rush as they completed drug charts. Nursing and pharmacy staff were observed having difficulty in identifying who was responsible for individual medication orders and then getting in touch with them with any queries.

\section{Phase 2: design of IDEAS prescription chart}

Findings from phase 1 led to some specific design specifications for the IDEAS chart that complemented recommendations from the AoMRC report. Given preferences across the professional groups derived from the focus groups, a booklet format was chosen and it was also decided that the IDEAS chart would be designed to be of sufficient length to avoid supplementary charts (eg, specific charts for medications such as warfarin or insulin, and repetitive transcriptions from one chart to another due to space running out). From observing behaviours on the ward and difficulties seen in using an existing chart documented from focus groups, an intuitive layout and ordering was chosen with separate sections for oxygen, anti-infectives and intravenous fluids. It was decided to try and incorporate some form of indexing so that people using the chart could quickly navigate to the relevant sections. Different settings and features suggested by the design team were tested with the wider project team that consisted of physicians, pharmacists and nursing staff. Behavioural scientists also suggested how a number of behavioural insights could also be incorporated into the design of the new IDEAS chart using a number of Mindspace effects (table 2, figures 1-4). The final IDEAS chart that was used for testing can be seen in online supplementary appendix 4 .

\section{Phase 3: in situ simulated pilot testing of IDEAS prescription chart}

A total of 29 foundation year doctors working at one hospital completed the evaluation; 14 completed the IDEAS chart and 15 the ICHNT chart. There was no significant difference between the numbers of medications prescribed on the IDEAS chart compared to ICHNT chart (164 of a possible 168 orders, vs 174 of a possible 180 orders; $\mathrm{p}=0.6$ ).

There were key differences in the degree to which medication orders were completed correctly using the two different charts (see table 3). Medication orders on the IDEAS chart showed a statistically nonsignificant improvement in legibility (164/164 vs 169/ 174; $\mathrm{p}=0.0611$ ). Medication orders on the IDEAS chart were significantly more likely to include correct dose entries $(164 / 164$ vs $166 / 174 ; p=0.0046)$ as well as contact information of the prescriber-both printed name $(163 / 164$ vs $0 / 174 ; \mathrm{p}<0.0001)$ and contact/ bleep number $(137 / 164$ vs 55/174; $\mathrm{p}<0.0001)$. Current prescribing guidelines specify that the prescriber should chart the frequency of medication administration and this was significantly more likely $(120 / 164$ vs $15 / 174 ; \mathrm{p}<0.0001)$ on the IDEAS chart. There was no 
Table 2 Mindspace elements incorporated in the IDEAS chart

\begin{tabular}{|c|c|c|}
\hline $\begin{array}{l}\text { Mindspace } \\
\text { intervention }\end{array}$ & Definition & Action \\
\hline Defaults & $\begin{array}{l}\text { People tend to go with the preset option or default } \\
\text { setting. This can be a problem with medication } \\
\text { orders where once prescribed, they can often } \\
\text { continue for days after the optimum duration of } \\
\text { treatment as a consequence of prescribers not } \\
\text { actively stopping them }\end{array}$ & $\begin{array}{l}\text { A separate section for antibiotic prescribing was } \\
\text { incorporated into the IDEAS chart, with the default } \\
\text { changed from one in which antibiotics continue to } \\
\text { be given to one in which they will only be given if a } \\
\text { clinician confirms that this is appropriate every } \\
3 \text { days (figure 1) }\end{array}$ \\
\hline Salience & $\begin{array}{l}\text { Salience refers to people's tendency to respond to } \\
\text { what is novel and relevant. Increasing the salience } \\
\text { of specific parts of the chart was attempted to } \\
\text { improve completion }\end{array}$ & $\begin{array}{l}\text { The allergy box in the IDEAS chart encourages } \\
\text { people to enter both the allergy and reaction. In } \\
\text { other areas, salient cues were used to reduce the } \\
\text { potential for ambiguity (figure 2) }\end{array}$ \\
\hline Priming & $\begin{array}{l}\text { People's behaviour and decision-making is } \\
\text { strongly influenced by subconscious cues in a } \\
\text { process called psychological priming }\end{array}$ & $\begin{array}{l}\text { In the IDEAS prescription chart, traditional } \\
\text { information based cues were replaced with an } \\
\text { example of how a prescription entry should look at } \\
\text { the start of the regular prescription section with the } \\
\text { aim of priming subsequent prescribing behaviour } \\
\text { (figure 3) }\end{array}$ \\
\hline $\begin{array}{l}\text { Checklist } \\
\text { (commitment } \\
\text { device) }\end{array}$ & $\begin{array}{l}\text { Checklists have a long history of use across many } \\
\text { high-risk industries and a safe surgery checklist } \\
\text { has been successfully implemented in hospital } \\
\text { operating rooms. }{ }^{20} \text { Checklists incorporate some of } \\
\text { the key features of commitment devices and } \\
\text { salience to provide checks and balances for safe } \\
\text { prescribing }\end{array}$ & $\begin{array}{l}\text { A checklist was added to the front page of the } \\
\text { IDEAS chart (figure 4). This focuses on three } \\
\text { problem areas where there is often a failure to } \\
\text { complete: (1) reaction type of any allergy (2) } \\
\text { duration and indication for antibiotic courses (3) } \\
\text { thromboembolism risk assessment (figure 4) }\end{array}$ \\
\hline
\end{tabular}

significant difference for the presence of signatures by prescribers $(163 / 164$ vs $171 / 174 ; \mathrm{p}=0.344)$ or in the documentation of allergy status and reaction.

We measured key outcomes related specifically to prescribing of the two antibiotics in the simulated case (table 4). The IDEAS chart significantly outperformed the ICHNT chart in prescribers indicating the duration of course $(26 / 28$ vs $15 / 29 ; p<0.0001)$ and the indication of anti-infective use $(28 / 28$ vs $17 / 29 ; \quad \mathrm{p}<0.0001)$ (table 4).

\section{DISCUSSION}

Professional organisations in the UK including the General Medical Council and Royal College of Nursing have called for standardised prescription charts to be used across the NHS with a standardised chart already used in hospitals across Wales. ${ }^{11}$ However, standardisation and good design are not the same thing and suboptimal chart design may facilitate medication errors. $^{12}{ }^{21}$ There is a clear case for good design and content of prescription charts and the guidance set by

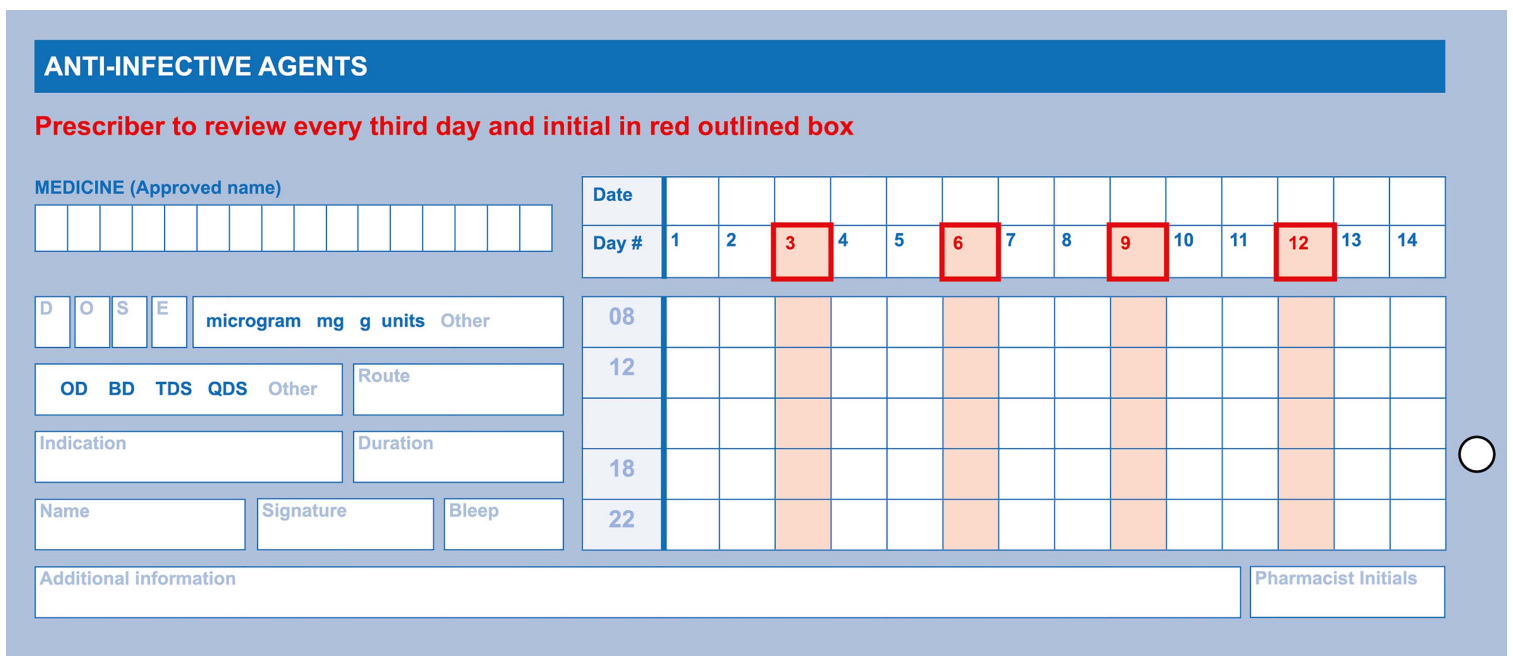

Figure 1 The anti-infective section of the IDEAS chart where prescribers need to confirm every 3 days that the antibiotic should continue to be given. 
Figure 2 Allergy box in an existing prescription chart (not ICHNT) (top) and the IDEAS chart (bottom).

\section{Complete for Allergies / Sensitivities or NKDA}

This section must be completed prior to administration of any medicine Include details of type of reaction

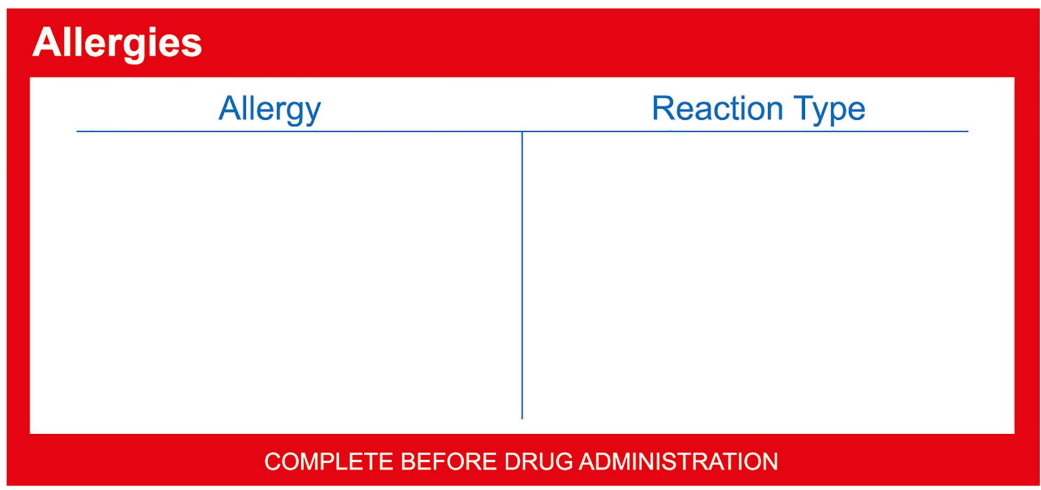

the AoMRC provides good suggestions. However, there is much we could learn about prescription chart design from the increased understanding we have of human judgment and decision-making through recent applied research in the behavioural sciences and user-centred design.
Few studies have investigated the physical context or environment in which prescribing takes place. This includes not just the sometimes hectic clinical environment that prescribing occurs in that has the potential to lead to errors but also the actual interface through which prescribing happens. ${ }^{24}{ }^{25}$ In a UK setting this

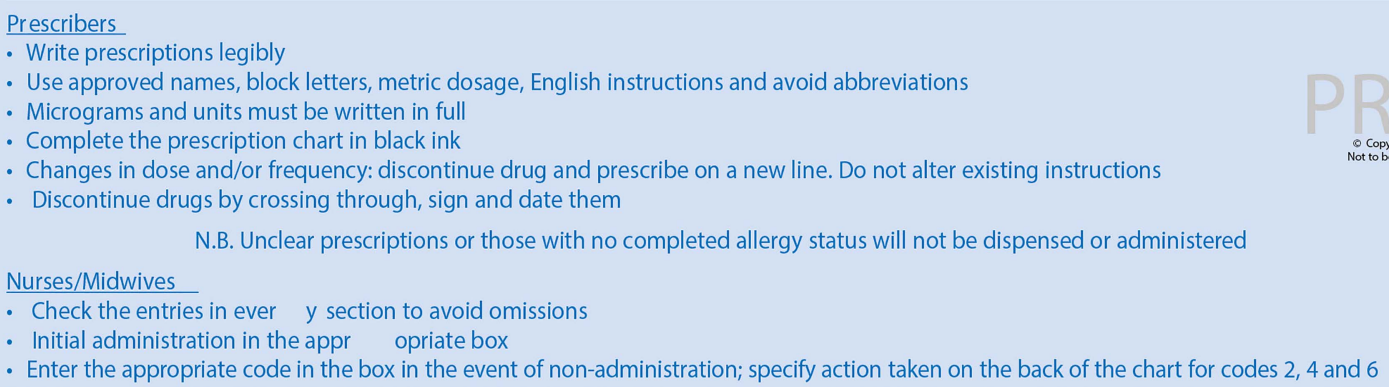

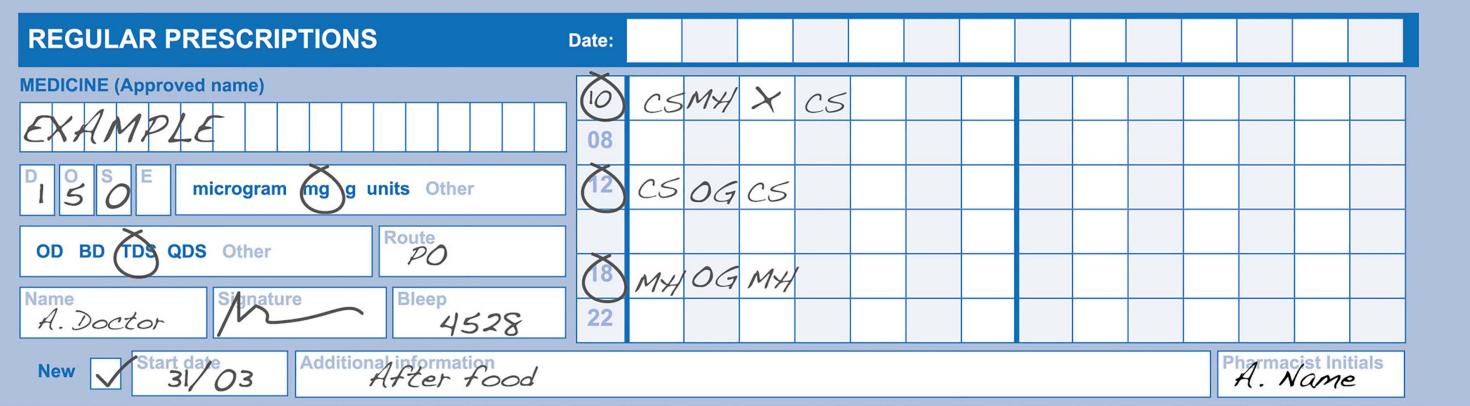

Figure 3 Instructions on prescribing found on an existing chart (ICHNT) (top) compared to 'priming' instruction from the IDEAS chart that encompasses all instructions (bottom). 


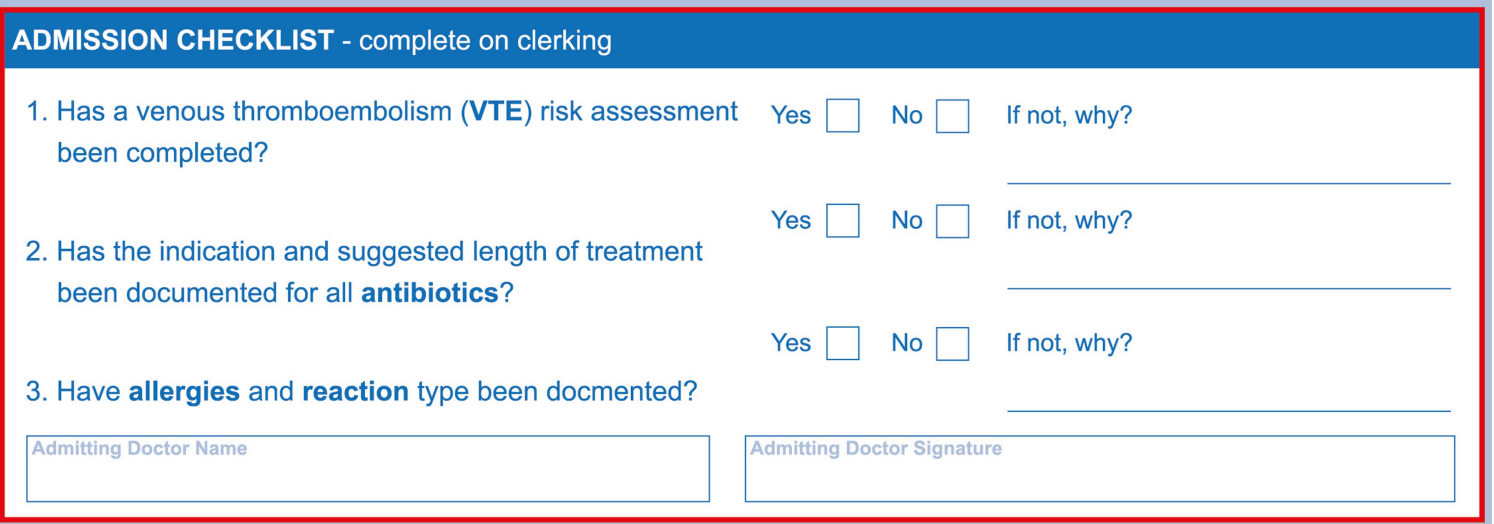

Figure 4 The checklist found on the front of the IDEAS chart.

interface continues to be largely through paper prescription rather than electronic systems. Certainly it is known that different prescription chart designs may be more likely than others to provoke error but little is known about how specific elements of chart design exert their influence. ${ }^{21}$ This is the first study to explore how behavioural and design insights can be used to improve prescription charts with the aim of reducing medication errors. While is not possible from this study to tease out the relative contribution of all the different features implemented through the IDEAS chart it appears that a combination of design changes (see box 1) does have an impact.

The IDEAS project has demonstrated, at least in a simulated context, that prescription chart design can lead to significant improvements in prescribing behaviour. These benefits were without any prior education or training using the IDEAS chart. It is notable that studies testing standardised charts have previously tended to include some training to support the implementation of the new chart. ${ }^{6}$ To reflect more usual practice, no such measures were taken in evaluating the IDEAS chart, indicating perhaps that a number of errors, like illegibility and poor prescriber identifiability, are rectifiable without the need for further extraneous interventions by addressing the choice architecture inherent in inpatient prescribing.

There is ongoing debate about the combination of tools that can deliver reduced numbers of prescription errors. Prescribing errors are often multifactorial with several active failures often conspiring together. The design of prescription charts is just one factor contributing to errors and the results of this study demonstrates that simple prescribing errors (legibility, ability to identify prescriber) were significantly reduced by changing chart design. While we have not shown that such errors would have led to actual patient harm, these errors if frequent are likely to have an impact on the delivery of safe and high-quality care.

We can use anti-infective prescribing as a lens to what good design of prescription charts can achieve. We know that anti-infectives are often incorrectly prescribed and this can lead to significant consequences such as inappropriate usage and prolonged courses. Inappropriate usage of anti-infectives can contribute to the emergence of antimicrobial resistance and healthcare acquired infections such as Clostridium difficile and the NHS has developed a strategy to ensure better antibiotic stewardship. ${ }^{26}$ A point

\begin{tabular}{|c|c|c|c|c|c|}
\hline & & $\begin{array}{l}\text { IDEAS } \\
\text { Chart } \\
\text { (\% of } 164 \\
\text { medication } \\
\text { orders) }\end{array}$ & $\begin{array}{l}\text { ICHNT } \\
\text { Chart } \\
\text { (\% of } 174 \\
\text { medication } \\
\text { orders) }\end{array}$ & $\begin{array}{l}\text { Significant } \\
\text { difference at } 5 \% \\
\text { level after } \\
\text { Holm-Bonferroni } \\
\text { (p value) }\end{array}$ & $\begin{array}{l}\text { IDEAS chart } \\
\text { shows significant } \\
\text { improvement } \\
\text { at } 5 \% \text { level } \\
\text { (p value) }\end{array}$ \\
\hline Was the prescription legible? & Yes & $164(100 \%)$ & 169 (97\%) & No $(0.061)$ & No difference \\
\hline Was the dose correctly entered? & Yes & $164(100 \%)$ & $166(95 \%)$ & Yes (0.007) & Yes $(0.0046)$ \\
\hline Was the prescriber's signature entered? & Yes & $163(99 \%)$ & $171(98 \%)$ & No $(0.623)$ & No difference \\
\hline Was prescriber's bleep number entered? & Yes & 137 (84\%) & $55(32 \%)$ & Yes $(<0.0001)$ & Yes $(<0.0001)$ \\
\hline $\begin{array}{l}\text { Was frequency of medications entered } \\
\text { correctly? }\end{array}$ & Yes & $\begin{array}{l}120(96 \%) \\
(n=125)\end{array}$ & $\begin{array}{l}15(11 \%) \\
(n=132)\end{array}$ & Yes $(<0.0001)$ & Yes $(<0.0001)$ \\
\hline $\begin{array}{l}\text { Was the prescriber's name entered and } \\
\text { legible }\end{array}$ & Yes & $163(99 \%)$ & $0(0 \%)$ & Yes $(<0.0001)$ & Yes $(<0.0001)$ \\
\hline
\end{tabular}


Table 4 Different completed features of antibiotic prescriptions using the IDEAS and ICHNT charts

\begin{tabular}{|c|c|c|c|c|c|}
\hline & & $\begin{array}{l}\text { IDEAS } \\
\text { Chart } \\
n=28 \text { ( } \% \text { of } \\
\text { total orders) }\end{array}$ & $\begin{array}{l}\text { ICHNT } \\
\text { Chart } \\
n=29 \text { (\% of } \\
\text { total orders) }\end{array}$ & $\begin{array}{l}\text { Significant } \\
\text { difference } \\
\text { at } 5 \% \text { level after } \\
\text { Holm-Bonferroni } \\
\text { (p value) }\end{array}$ & $\begin{array}{l}\text { IDEAS Chart } \\
\text { shows significant } \\
\text { improvement } \\
\text { at } 5 \% \text { level? } \\
\text { (p value) }\end{array}$ \\
\hline Is the duration of course documented? & Yes & $26(93 \%)$ & $15(52 \%)$ & $<0.0008$ & Yes $(<0.0001)$ \\
\hline Is the indication for antibiotics indicated? & Yes & $28(100 \%)$ & $17(59 \%)$ & 0.0001 & Yes $(<0.0001)$ \\
\hline Is contact (bleep number) entered? & Yes & $24(86 \%)$ & $9(31 \%)$ & $<0.001$ & Yes $(<0.0001)$ \\
\hline Is the prescriber name entered and legible? & Yes & $27(96 \%)$ & $0(0 \%)$ & $<0.001$ & Yes $(<0.0001)$ \\
\hline
\end{tabular}

prevalence study from 2008 found that $23.9 \%$ of antibiotic prescriptions were illegible and $29.9 \%$ incomplete. ${ }^{27} \mathrm{~A}$ key problem encountered with anti-infectives is that the rationale for usage and proposed course of treatment is often poorly documented. It is recommended by the majority of hospitals that in addition to standard requirements, all anti-infective prescriptions must have an indication and have a stop/review date, ${ }^{26}$ but current charts often do not encourage this. By having a dedicated anti-infectives section with separate entry boxes for indication and suggested length of treatment, $100 \%$ of prescribers completing the IDEAS chart specified the reason for prescribing them. This was a significant improvement when compared to the existing ICHNT chart where only $59 \%$ of prescribers

Box 1 Recommended features of an 'intelligent' inpatient prescription chart, based on our findings

1. A booklet format with essential patient details visible on each subsequent page achieved through a cut out section

2. Separate sections for drug allergy and specific reactions, saliently visible on every page of the chart

3. Intelligent and intuitive layout of different sections (eg, regular medications, as required medications) with an index to allow easy navigation

4. Specific section for prescribing anti-infectives with particular attention on separate spaces for documenting duration and indication

5. Use of a 'checklist' at the beginning of chart to ensure initial prescriber completes certain tasks. The questions can be based on local needs

6. Simplified thromboembolism risk assessment with added guidance for prescribers based on local guidelines

7. Use of colouring within the chart that directs attention to important areas (eg, allergy box)

8. Provision of separate spaces for different requests for information (eg, separate boxes for prescriber's signature, name and bleep rather than grouping them into one)

9. Gridlines in text boxes to encourage chart users to write in block capitals

10. Avoidance where possible of free text and preference for use of written choices and checkboxes

11. Provision of an example of how prescribers should write up medication orders to 'prime' subsequent prescribing behaviour

12. Simplified system for administration codes to more clearly identify problems in giving medications specified the indication. No new education or training was required to shift this change in prescribing behaviour; it came about as a consequence of dedicated entry boxes and a separate anti-infectives section.

Despite the inevitable move towards electronic prescribing in the UK, progress has been slow and it is likely to be many years before electronic systems have taken over from paper prescription charts. ${ }^{9}$ In the meantime, significant improvements in prescribing could be realised by implementing some of the findings of the IDEAS project. Making small changes to the choice environment can be used as an effective behaviour change mechanism, prompting individuals to change their behaviours in ways that make prescribing safer and more effective. A number of hospitals are using learning from this work to develop enhanced prescription charts locally and we are now working towards a formal trial of the IDEAS prescription chart following its implementation.

\section{CONCLUSIONS}

The IDEAS prescription chart-at least in a simulated context-significantly reduced a number of frequent prescribing errors including dosing errors and illegibility. It also served to increase prescriber identifiability and enhance information documentation in relation to antibiotic prescribing. Significant and positive changes in prescribing behaviours took place without the need for extra training and education. A wider clinical evaluation is required but the learning developed through the IDEAS project could contribute to better-designed prescription charts that facilitate improved prescribing.

\section{Author affiliations}

${ }^{1}$ Imperial College London, St Mary's Hospital, London, UK

${ }^{2}$ School of Pharmacy, University College London, London, UK

${ }^{3}$ Centre for Infection Prevention and Management, Imperial College London, London, UK

${ }^{4}$ Imperial College Healthcare NHS Trust, London, UK

${ }^{5}$ Centre for Medication Safety, Imperial College Healthcare NHS Trust and UCL School of Pharmacy, London, UK

Contributors DK, EC, CB, IV, GM and MG contributed to the design of the work, acquisition of data and interpretation. AJ and ZW contributed to the acquisition of the data and interpretation. $A D$ and BDF contributed to the design of the work and interpretation. All authors listed contributed to the drafting of the work and revisions. All authors gave their final approval of the final manuscript submitted. 
Funding The Imperial Drug Chart Evaluation and Adoption Study (IDEAS) was supported by a grant from the Behavioural Insights Team - which at the time of funding was part of the UK Cabinet Office. This work is supported by (1) the National Institute for Health Research Biomedical Research Centre Funding Scheme at Imperial College London (funding number not applicable) and the National Centre for Infection Prevention and Management (CIPM) funded by the UK Clinical Research Council (UKCRC G0800777), (2) The National Institute of Health Research (NIHR) Imperial Patient Safety Translational Research Centre and (3) the NIHR Health Protection Research Unit (HPRU) in Healthcare Associated Infection and Antimicrobial Resistance at Imperial College London in partnership with Public Health England (PHE). Competing interests None.

Provenance and peer review Not commissioned; externally peer reviewed.

Data sharing statement Extra data can be accessed via the Dryad data repository at http://datadryad.org/ with the doi:10.5061/dryad.sk040.

Open Access This is an Open Access article distributed in accordance with the Creative Commons Attribution Non Commercial (CC BY-NC 4.0) license, which permits others to distribute, remix, adapt, build upon this work noncommercially, and license their derivative works on different terms, provided the original work is properly cited and the use is non-commercial. See: http:// creativecommons.org/licenses/by-nc/4.0/

\section{REFERENCES}

1. Gommans J, Mclntosh $\mathrm{P}$, Bee $\mathrm{S}$, et al. Improving the quality of written prescriptions in a general hospital: the influence of 10 years of serial audits and targeted interventions. Intern Med $J$ 2008;38:243-8.

2. Aronson JK. Medication errors: definitions and classification. $\mathrm{Br} \mathrm{J}$ Clin Pharmacol 2009;67:599-604.

3. Montesi G, Lechi A. Prevention of medication errors: detection and audit. Br J Clin Pharmacol 2009;67:651-5.

4. Dean B, Schachter M, Vincent C, et al. Causes of prescribing errors in hospital inpatients: a prospective study. Lancet 2002;359:1373-8.

5. Williams D. Medication errors. J R Coll Physicians Edinb 2007;37:343-6.

6. Coombes ID, Stowasser DA, Reid C, et al. Impact of a standard medication chart on prescribing errors: a before-and-after audit. Qual Saf Health Care 2009;18:478-5.

7. Leape LL, Bates DW, Cullen DJ, et al. Systems analysis of adverse drug events. ADE Prevention Study Group. JAMA 1995;274:35-43.

8. Lewis PJ, Dornan T, Taylor D, et al. Prevalence, incidence and nature of prescribing errors in hospital inpatients: a systematic review. Drug Saf 2009;32:379-89.

9. Ahmed Z, McLeod MC, Barber N, et al. The use and functionality of electronic prescribing systems in English acute NHS trusts: a cross-sectional survey. PloS ONE 2013;8:e80378.
10. Franklin BD, Reynolds M, Shebl NA, et al. Prescribing errors in hospital inpatients: a three-centre study of their prevalence, types and causes. Postgrad Med J 2011;87:739-45.

11. Academy of Medical Royal Colleges. Standards for the design of hospital in-patient prescription charts. 2011. http://www.aomrc.org. uk/doc_view/9416-standards-for-the-design-of-hospital-in-patientprescription-charts (accessed 28 Nov 2014).

12. Barber N, Franklin BD, Jacklin A. Of snarks, boojums and national drug charts. J R Soc Med 2013;106:6-8.

13. Hogerzeil HV. Promoting rational prescribing: an international perspective. Br J Clin Pharmacol 1995;39:1-6.

14. Ross S, Loke YK. Do educational interventions improve prescribing by medical students and junior doctors? A systematic review. $\mathrm{Br} \mathrm{J}$ Clin Pharmacol 2009;67:662-70.

15. Hartel MJ, Staub LP, Roder $\mathrm{C}$, et al. High incidence of medication documentation errors in a Swiss university hospital due to the handwritten prescription process. BMC Health Serv Res 2011;11:199.

16. Dolan P, Hallsworth D, Halpern D, et al. Influencing behaviour: the mindspace way. J Econ Psychol 2012;33:264-77.

17. Dolan P, Hallsworth M, Halpern D, et al. Mindspace: influencing behaviour through public policy. London: Cabinet Office, 2010.

18. Ariely D. Predictably irrational: the hidden forces that shape our decisions. London: Harper Collins, 2008.

19. Thaler R, Sunstein C. Nudge: improving decisions about health, wealth and happiness. New Haven: Yale University Press, 2008.

20. Hollands GJ, Shemilt I, Marteau TM, et al. Altering micro-environments to change population health behaviour: towards an evidence base for choice architecture interventions. BMC Public Health 2013;13:1218.

21. Tallentire VR, Hale RL, Dewhurst NG, et al. The contribution of prescription chart design and familiarity to prescribing error: a prospective, randomised, cross-over study. BMJ Qual Saf 2013;22:864-9.

22. Patterson MD, Blike GT, Nadkarni VM. In situ simulation: challenges and results. In: Henriksen K, Battles JB, Keyes MA, Grady ML, eds. Advances in patient safety: new directions and alternative approaches (vol 3: performance and tools). Advances in patient safety. Rockville, MD: Agency for Healthcare Research and Quality, 2008.

23. Dean B, Schachter M, Vincent C, et al. Prescribing errors in hospital inpatients: their incidence and clinical significance. Qual Saf Health Care 2002;11:340-4

24. Tully MP, Ashcroft DM, Dornan T, et al. The causes of and factors associated with prescribing errors in hospital inpatients: a systematic review. Drug Saf 2009;32:819-36.

25. Czaja R, Blair J. Designing Surveys: A Guide to Decisions and Procedures. London: Sage Publications, 2005.

26. Ashiru-Oredope $D$, Sharland M, Charani E, et al. Improving the quality of antibiotic prescribing in the NHS by developing a new Antimicrobial Stewardship Programme: start smart-then focus. $J$ Antimicrob Chemother 2012;67(Suppl 1):i51-63.

27. Calligaris L, Panzera A, Arnoldo L, et al. Errors and omissions in hospital prescriptions: a survey of prescription writing in a hospital. BMC Clin Pharmacol 2009;9:9. 